\title{
Stickler syndrome type 3
}

INSERM

\section{Source}

INSERM. (1999). Orphanet: an online rare disease and orphan drug data base. Stickler syndrome type 3. ORPHA:166100

Stickler syndrome type 3 is a rare, genetic, multiple congenital anomalies/dysmorphic syndrome characterized by craniofacial dysmorphism (midface hypoplasia, depressed nasal bridge, small nose with upturned tip, cleft palate, Pierre Robin sequence), bilateral, pronounced sensorineural hearing loss, and skeletal/joint anomalies (including spondyloepiphyseal dysplasia, arthralgia/arthropathy), in the absence of ocular abnormalities. 